\title{
Contrast enhancement through structural variations in the rhabdoms of oplophorid shrimps.
}

\author{
E. Gaten P. M.J. Shelton M. S. Nowel
}

E. Gaten P.M.J. Shelton

Department of Biology, University of Leicester, University Road

Leicester LE1 7RH, UK

TELEPHONE +44(0)116 2523387

FAX $\quad+44(0) 1162523330$

E-MAIL gat@le.ac.uk

M. S. Nowel

Department of Biology, Providence College, Providence, Rhode Island 02918-0001, USA 


\begin{abstract}
Rhabdom morphology in oplophorid shrimps varies both interspecifically and also within the eye of an individual, particularly with respect to the relative sizes of distal and proximal rhabdoms. In this study we have combined published data on anatomical measurements, visual pigment absorption and underwater light distribution to model the absorptance of light from different sources by the rhabdoms in these shrimps. In Systellaspis debilis the violet-sensitive distal rhabdom is prominent and increases in size along a dorso-ventral gradient. The model shows that the dorsal ommatidia are efficient at detecting downwelling irradiance and photophore emissions. In more ventral regions of the eye, the enlarged distal rhabdom results in the ommatidia in this region being more sensitive to eyeshine from other shrimps and to their bioluminescent secretions. This will improve the contrast of such light sources against the background space light. Acanthephyra pelagica has virtually no distal rhabdom and the model shows that this arrangement results in greater sensitivity.
\end{abstract}




\section{Introduction.}

The unique light environment of the mesopelagic zone presents the inhabitants of this region with a number of visual problems. The attenuation of light with depth, resulting in the absence of usable daylight below $1000 \mathrm{~m}$, means that sensitivity must be maximized. The asymmetrical distribution of light in the deep seas, with the downwelling irradiance up to 1000 times brighter than the upwelling irradiance, is often correlated with structural modifications along the dorso-ventral plane of the eye (Lythgoe, 1979; Land et al., 1979; Land, 1989; Gaten et al., 2002). In addition, scattering of light results in a low contrast visual scene in which any target is obscured by veiling light.

Oplophorid shrimps are amongst the most important inhabitants of the mesopelagic zone. They have reflecting superposition eyes with large rhabdoms, characteristics that lead to high sensitivity. Several anatomical studies have described interspecific and intraspecific variations in eye morphology that are related to the depths at which the species are normally found (Welsh \& Chace, 1937, 1938; Gaten et al., 1992, 2003). In particular, considerable variations in the relative sizes of the distal and proximal rhabdoms have been described (Gaten et al., 2003), although the reason for these differences has not been fully explained. The distal rhabdom varies in size from those of Systellaspis debilis, where it forms up to $25 \%$ of the total rhabdom volume, to those of Acanthephyra pelagica, where it is detectable only by electron microscopy (Gaten et al., 2003). Some oplophorids have been shown to be sensitive to both violet and blue-green light by the use of electrophysiogical 
(Frank \& Case, 1988) and behavioural means (Frank \& Widder, 1994a, 1994b). In Systellaspis debilis the distal rhabdom has been shown to absorb maximally at $410 \mathrm{~nm}$ in contrast to the main rhabdom which has a peak absorption at $498 \mathrm{~nm}$ (Cronin \& Frank, 1996). Rhabdom morphology in this species also varies dorso-ventrally, with the relative size of the distal rhabdom increasing ventrally (Gaten et al., 2003).

In the present paper, an investigative model has been constructed which uses published data on visual pigments and anatomical measurements of two species of oplophorid shrimps. The efficiency with which this model eye absorbs light from various sources available in the mesopelagic zone is then used to suggest why some oplophorid shrimps have apparently lost the distal rhabdom during development, why the distal rhabdom varies regionally within the eyes of others, and why deepsea shrimps should possess a visual pigment with peak sensitivity in the violet region of the spectrum.

\section{Materials \& methods.}

Six light sources available to mesopelagic shrimps were considered: downwelling irradiance, upwelling irradiance, bioluminescent secretions, bioluminescent photophore emissions and reflections from oplophorid carapace and tapetum. The downwelling light spectrum was based on that recorded at a depth of $480 \mathrm{~m}$ in the North Atlantic (Kampa, 1970), close to the region where our specimens were obtained. For each wavelength, the irradiance values given in Kampa (1970) were converted from radiation flux to quanta $\mathrm{s}^{-1}$ and extrapolated to $380 \mathrm{~nm}$ based on the data recorded by Frank \& Widder (1996) from depths in excess of $400 \mathrm{~m}$. There is no 
recorded data for upwelling light from the depths at which mesopelagic shrimp are normally found so the downwelling data above was modified according to the irradiance reflectance properties recorded at a depth of $15 \mathrm{~m}$ in the Gulf Stream (Tyler \& Smith, 1970). The upwelling light is approximately $0.5 \%$ of the downwelling light in typical low-scattering deep oceanic water (Denton, 1990). However, not all wavelengths are backscattered equally; the irradiance reflectance can be as high as $10 \%$ for short wavelength light compared to $0.1 \%$ for red light (Kirk, 1983).

Data on the reflectivity of the carapace and tapetum of Systellaspis debilis (N. J. Marshall, pers. com.) were used to modify the values for downwelling irradiance. The spectral radiance (photons. $\mathrm{m}^{-2} \cdot \mathrm{s}^{-1} \cdot \mathrm{sr}^{-1}$ ) of the carapace was estimated by multiplying the downwelling spectrum by the reflectance at each wavelength. To obtain the spectral radiance of eyeshine, the downwelling irradiance was attenuated to simulate passage through the rhabdom, modified by multiplying by the tapetal reflectance value for each wavelength, and attenuated again by further absorption within the rhabdom. Spectra of bioluminescent secretions and photophore output of Oplophorus spinosus were taken from Herring (1983).

The data for all light sources were entered into a spreadsheet to give the relative photon flux at the eye for each wavelength ( $1 \mathrm{~nm}$ intervals). The fraction, $F(\lambda)$, of this light absorbed by the rhabdom was calculated successively for the distal and proximal rhabdoms and then, following reflection at the tapetum, for proximal and distal rhabdoms. This fraction, also known as the absorptance, is the ratio of quanta absorbed to quanta incident. This value is normally quoted as a percentage. 


$$
F(\lambda)=1-e^{-k \cdot A(\lambda) l}
$$

where $k \cdot A(\quad)$ is the absorption coefficient, $k$, multiplied by the relative absorbance (A) at wavelength $\lambda$ and $l=$ rhabdom length (Warrant \&Nilsson, 1998). The absorbance values were obtained by fitting the template of Stavenga et al. (1993) to the published values of $k$ (proximal $=0.01 \mu \mathrm{m}^{-1}$, distal $=0.006 \mu \mathrm{m}^{-1}$ ) and the peak absorbance wavelengths for the rhabdoms (proximal $=498 \mathrm{~nm}$, distal $=410 \mathrm{~nm}$ ) of Systellaspis debilis (Cronin \& Frank, 1996). The values of $l$ for each rhabdom type are shown in Table 1 (from Gaten et al., 2003). The proportions of incident photons absorbed by the whole rhabdom and by the distal and proximal rhabdoms separately were then calculated.

Table 1. Systellaspis debilis. Mean lengths of distal and proximal rhabdoms in five regions of the eye (after Gaten et al., 2003).

\begin{tabular}{|c|c|c|}
\hline eye region & rhabdom type & length $(\mu \mathrm{m})$ \\
\hline \multirow{2}{*}{ dorsal } & distal & 21 \\
\hline & proximal & 140 \\
\hline \multirow{2}{*}{ dorso/lateral } & distal & 34 \\
\hline & proximal & 146 \\
\hline \multirow{2}{*}{ lateral } & distal & 38 \\
\hline & proximal & 116 \\
\hline \multirow{2}{*}{ ventro/lateral } & distal & 45 \\
\hline & proximal & 113 \\
\hline \multirow{2}{*}{ ventral } & distal & 40 \\
\hline & proximal & 76 \\
\hline
\end{tabular}


Similar calculations for each light source were made using a single visual pigment model based on morphological data for Acanthephyra pelagica (Gaten et al., 2003) and the absorbance spectrum for A. purpurea with a maximum sensitivity $\left(\lambda_{\max }\right)$ at 492 nm (Kent, 1997), fitted as above (Stavenga et al., 1993).

\section{Results.}

The spectral compositions of the light sources used in the model are shown in Fig. 1. The downwelling irradiance measured in the North Atlantic (Kampa, 1970) had a peak transmission wavelength of $476 \mathrm{~nm}$. As a result of wavelength selective backscattering, the upwelling irradiance shows a shift in $\lambda_{\max }$ to around $463 \mathrm{~nm}$, accompanied by a significant decrease in the amount of light above $480 \mathrm{~nm}$ (Fig. 1A). Following reflection from oplophorid carapace, the curve for downwelling irradiance was not altered significantly $\left(\lambda_{\max }=473 \mathrm{~nm}\right)$. The spectrum obtained following tapetal reflection was considerably modified both by the reflective properties of the tapetum and absorption within the rhabdoms before output from the eye. The peak was shifted to $457 \mathrm{~nm}$ and there was a relative reduction in the proportion of light at all wavelengths longer than this (Fig. 1A).

Oplophorid shrimps generally show a difference of $10-15 \mathrm{~nm}$ in $\lambda_{\max }$ between their bioluminescent secretion and photophore emission spectra (Herring, 1983). The output of the photophores of Oplophorus spinosus matched the downwelling light (except along the long wavelength arm of the curve) whereas the peak emission of the secretion is shifted to around $460 \mathrm{~nm}$ (Fig. 1B). 

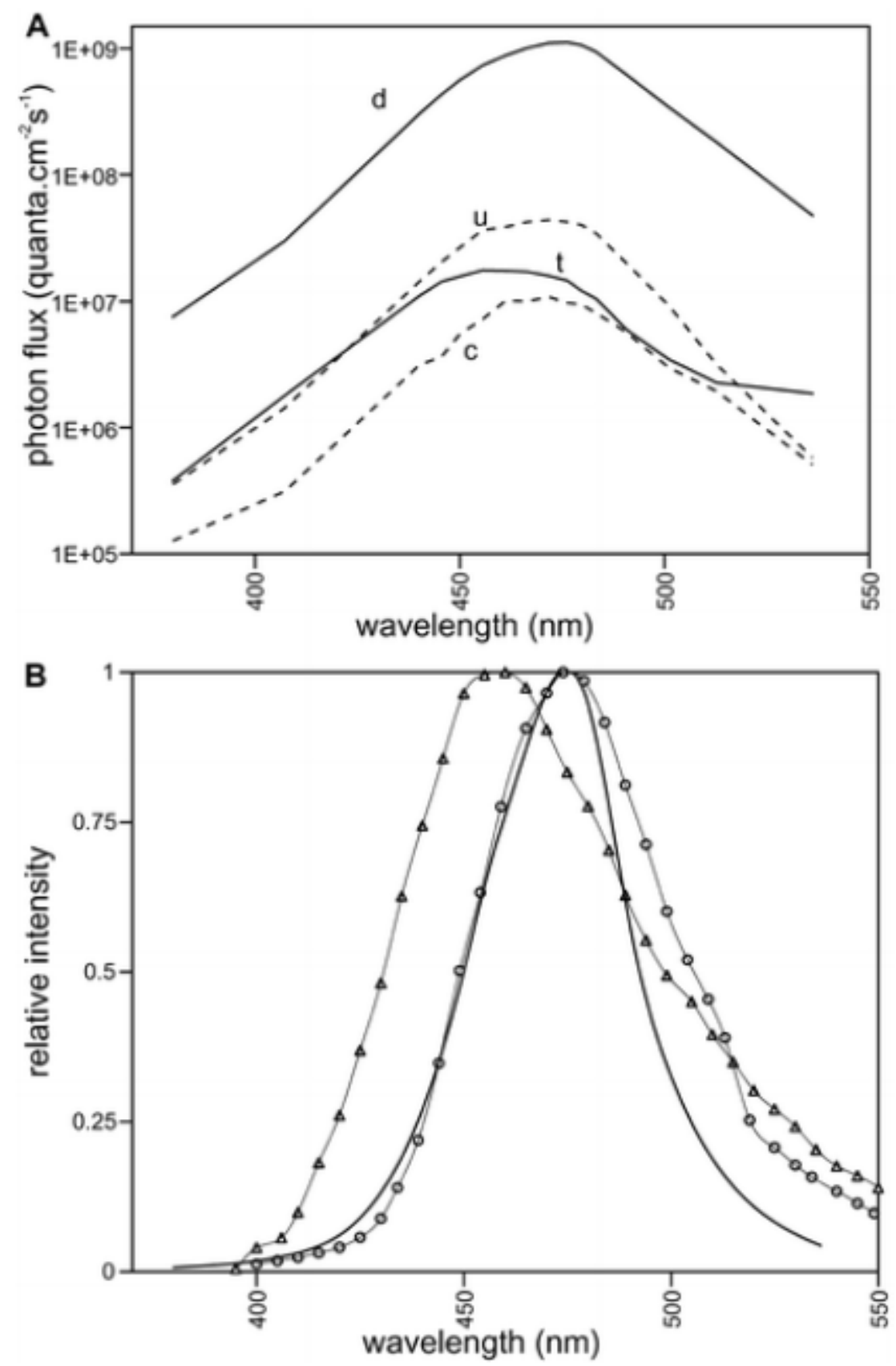

Fig. 1. Spectra of the light sources used in the model. A - quantal distribution (on a log scale) of the downwelling irradiance at a depth of 480 $\mathrm{m}$ (d) and modifications of this spectrum to give the upwelling irradiance (u), the spectrum reflected from an oplophorid carapace (c) and that resulting from tapetal reflection $(\mathrm{t})$. B - relative spectral distribution of the downwelling irradiance (no symbol), showing how this is closely matched by the photophore output (open circle). The bioluminescent secretion (open triangle) has a shorter peak emission wavelength. 
The relative absorption of light in the modeled eye of Systellaspis debilis by distal $\left(F_{d}\right)$ and proximal rhabdoms $\left(F_{p}\right)$ varied depending on the region of the eye and the light source. The distal rhabdoms in the dorsal part of the eye generally absorbed less light compared to those in more ventral regions (Fig. 2A). Values of $F_{d}$ were highest for tapetally reflected light (up to $12.1 \%$ ) and lowest for photophore emissions (down to $2.34 \%$ ). Absorption of light by the proximal rhabdom (Fig. 2B) was highest dorsally and decreased towards the ventral region. The highest values of $F_{p}$ were obtained for photophore emissions $(86.6 \%)$ and the lowest for tapetal reflections (up to $77.5 \%$ ).

Due to the size of the rhabdoms, the relatively high absorption coefficients and the effect of the tapetum, the proportion of incident light $(F)$ absorbed by the whole rhabdom was high for all light sources. With the exception of the ventral region, all parts of the model eye of Systellaspis debilis absorbed between $80 \%$ and $90 \%$ of the incident quanta (Fig. 2C). The ventral rhabdoms, with a mean total length of around $115 \mu \mathrm{m}$ (compared to a mean of $163 \mu \mathrm{m}$ for the rest of the eye) absorbed only $68 \%$ to $73 \%$ of the light. For all light sources, the highest value of $F$ was recorded for the dorso-lateral rhabdoms followed by the dorsal rhabdoms. Absorption of photophore emissions was most efficient (up to $90.27 \%$ ) whereas absorption of tapetal reflections was least efficient (up to $85.61 \%$ ). 

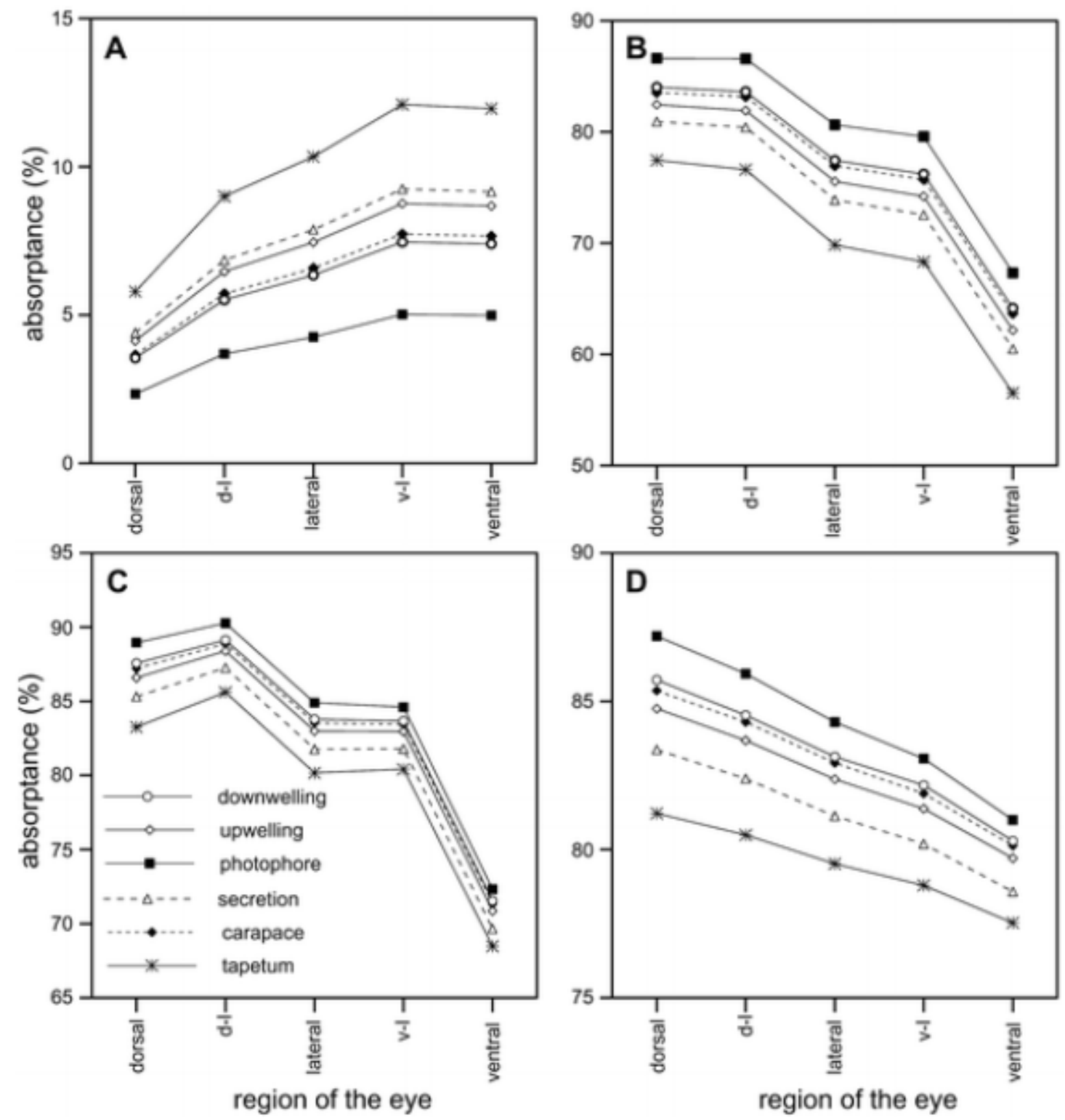

Fig. 2. Systellaspis debilis Absorption of light predicted by the model in five regions of the eye from six light sources (the symbols used in $\mathrm{C}$ apply to all graphs). A - Absorptance by the distal rhabdom $\left(F_{d}\right)$. B - Absorptance by the proximal rhabdom $\left(F_{p}\right)$. C - Absorptance of light $(F)$ by whole rhabdoms. D - Data from C recalculated assuming a constant rhabdom length $(150 \mu \mathrm{m})$ with the sizes of the distal and proximal rhabdoms adjusted proportionally.

The regional changes in the numbers of photons absorbed were due to the variations in the overall lengths of the rhabdoms and the relative contributions of the distal and proximal rhabdoms. To show the effect of changes in the distal/proximal ratio the calculations were repeated using a constant rhabdom 
length $(150 \mu \mathrm{m})$ with the lengths of the distal and proximal rhabdoms adjusted proportionally. This results in a linear decrease from dorsal to ventral in the values of $F$ obtained (Fig. 2D).

Values of $F$ were calculated for the rhabdoms in the lateral part of the eye of Acanthephyra pelagica using a $\lambda_{\max }$ of $492 \mathrm{~nm}$ recorded for the closely related species A. purpurea (Kent, 1997). The values obtained were comparable to those calculated for the lateral rhabdoms of Systellaspis debilis for all light sources even though the rhabdoms of $A$. pelagica were shorter (mean length $130 \mu \mathrm{m}$ ). When the calculations were repeated for a rhabdom $150 \mu \mathrm{m}$ long an increase in absorption of between 3 and $4 \%$ was obtained for all light sources (Table 2). As a result of this, higher values of $F$ were recorded for all light sources when compared to $150 \mu \mathrm{m}$ rhabdoms of $S$. debilis (Fig. 2D).

Table 2. Acanthephyra purpurea. Absorptance, F, (\%) of light from six sources by 130 and $150 \mu \mathrm{m}$ long rhabdoms containing a single visual pigment. The absorptances predicted by the model for A. purpurea with a max of $492 \mathrm{~nm}$ (Kent, 1997) are shown.

\begin{tabular}{|c|c|c|c|c|c|c|c|}
\hline wavelength & $\begin{array}{l}\text { rhabdom } \\
(\mu \mathrm{m})\end{array}$ & downwelling & upwelling & photophore & secretion & carapace & tapetum \\
\hline $492 \mathrm{~nm}$ & 130 & 85.91 & 85.11 & 87.15 & 82.96 & 85.52 & 85.84 \\
\hline 4.purpurea & 150 & 89.29 & 88.59 & 90.41 & 86.66 & 88.93 & 89.22 \\
\hline
\end{tabular}

\section{Discussion.}

Behavioural sensitivity measurements have shown that oplophorid shrimps whose eyes contain two visual pigments are equally sensitive to light at 400 and 500 
nm. In contrast, where only one pigment is present, a threshold response to light at $400 \mathrm{~nm}$ required up to one log unit more light than that required for a threshold response to light at $500 \mathrm{~nm}$ (Frank \& Widder, 1994a, 1994b). Such experiments show that these shrimps use near-UV light and it has been shown that usable amounts of light at $380 \mathrm{~nm}$ are present at $600 \mathrm{~m}$, the maximum daytime depth of Systellaspis debilis (Frank \& Widder, 1996). The use of an investigative model in the current paper suggests why shrimps such as Systellaspis debilis have distal rhabdoms which vary in size along a dorso-ventral gradient whilst others such as Acanthephyra pelagica have not retained the distal rhabdom.

Although the model indicates that the fraction of the incident quanta that are absorbed $(F)$ is high, the values quoted in the literature are generally higher (e.g. 99\%; Hiller-Adams et al., 1988). This is because the earlier values have been calculated assuming that the absorption coefficient at peak absorbance applies to all other wavelengths. In the present study the absorption coefficient for each wavelength has been calculated as shown in equation (1) above (Warrant \& Nilsson, 1998).

Values of $F$ predicted by the model fell mostly between $80 \%$ and $90 \%$. The factors contributing to the high values of $F$ are the rhabdom length (assumed to be twice the anatomical length due to tapetal reflection) and the high value of $k$ for the proximal rhabdom which, at $0.01 \mu \mathrm{m}^{-1}$, is higher than for most crustacean visual pigments (T. Cronin, pers. com.). The highest values of $F$ were obtained for the dorsal and dorsolateral rhabdoms of Systellaspis debilis due to the long rhabdoms seen in this region and to the reduced length of the distal rhabdom. The lower value of $k$ for the distal 
rhabdom (0.006: Cronin \& Frank, 1996) contributed to the reduced value of $F$ calculated for the ventral half of the eye in which the distal rhabdom is more prominent. The light sources for which the highest values of $F$ were obtained were downwelling light, carapace reflection (which did not change the downwelling spectrum significantly) and photophore emissions (that were closely matched to the downwelling spectrum). Lower values of $F$ were obtained for the other light sources, where the spectral distribution was shifted to shorter wavelengths. This occurred through selective backscattering in upwelling light and absorption by the rhabdoms in the case of tapetal reflection. The emission spectrum peak of bioluminescent secretion is around $15 \mathrm{~nm}$ shorter than that of the downwelling light (Herring, 1983).

The results of the model showed that relative absorption of light by the distal rhabdom $\left(F_{d}\right)$ follows the opposite trend. Values of $F_{d}$ were highest for upwelling light, tapetal reflections and bioluminescent secretions, where the spectra are shifted to shorter wavelengths. The maximum ratio of $F_{d} / F_{p}$ was $1 / 5.6$ although it cannot be assumed that the responses of the receptor cells would be in a similar ratio. In decapods, the axons from R8 (the retinula cell that forms the distal rhabdom) terminate in the medulla externa whereas those from the other retinula cells project to the lamina ganglion (Nässel, 1976). Some preprocessing of the signal normally occurs in the lamina (Laughlin, 1981), so it is to be expected that the signals from the two sources would not be in proportion to the numbers of photons absorbed.

Behavioural experiments showed no significant difference in the light levels at 400 and $500 \mathrm{~nm}$ required to elicit a threshold response (Frank \& Widder, 1994b) so the 
response to the input from the distal rhabdom is high despite the small numbers of photons absorbed there.

Various theories have been advanced to explain why deep-sea animals should have near-UV sensitivity. It has been suggested that the detection of changes in the spectrum at dusk may be used to trigger the vertical migrations seen in many mesopelagic shrimp (Frank \& Widder, 1994a). However, it has since been shown that these changes are not visible at the depths inhabited by the shrimp (Frank \& Widder, 1996). Another suggestion was that the depth at which the animals live could be gauged by detecting the spectral bandwidth of the downwelling light. This was originally proposed for alciopid worms (Wald \& Rayport, 1977). In another approach, the correlation between the presence of two visual pigments and the possession of ventral photophores led to a suggestion that there may be a causal link between the two (Frank and Widder, 1994b). This may be advantageous for congener recognition, as reported for some deep-sea fish (Partridge et al., 1988), or for perfecting the camouflage of the shrimp by precise matching of the photophore output to the downwelling spectrum (Frank \& Widder, 1994b). All of these proposals suggest a need for modification of the rhabdoms in the dorsal part of the eye as this is the region responsible for scanning both those photophores associated with counter illumination (which always point downwards - Nowel et al., 1998) and the downwelling light. As the rhabdoms in this region retain the structure seen in shallow-water shrimps, whereas those in the ventral part of the eye are modified, all of these suggestions seem doubtful. 
The use of two visual pigments offset from the peak wavelength of the background light should be more efficient for contrast detection (Lythgoe, 1968). Although the total absorption of light is reduced when compared to a single visual pigment, the ability to differentiate between background spacelight and light from other targets would represent a distinct advantage. This could be achieved through the different ratios of $F_{d} / F_{p}$. Thus, the oplophorid shrimps with two visual pigments appear to be adapted for improved contrast detection which should allow them to differentiate between the radiance characteristics of various targets (such as carapace or tapetal reflections and bioluminescent secretions) and that of the background spacelight.

The difference in the ratio $F_{d} / F_{p}$ is small when comparing reflections from the oplophorid carapace against upwelling light, but it may be larger for prey species. Larger differences are seen when bioluminescent secretions and tapetal reflections are compared to the background against which they would be viewed. Bioluminescent emission spectra of fish have $\lambda_{\max }$ values mostly in the range 470 $500 \mathrm{~nm}$ (Herring, 1983), which are equal to or greater than that of the downwelling light. In contrast, all species of oplophorid shrimp have an alarm response involving a blue luminescent secretion with $\lambda_{\max }$ between 450 and $460 \mathrm{~nm}$. It is unlikely that the two-pigment oplophorid eye could detect the small differences in emission spectra necessary to differentiate between different species of oplophorid, although they may be able to differentiate between shrimp and fish bioluminescence. 
Distinguishing tapetal reflections from the background should be possible given the maximal ratio of $F_{d} / F_{p}$ predicted by the model. The tapetum is a valuable aid to sensitivity in deep-sea animals, effectively doubling the length of the rhabdom. This provides a substantial increase in sensitivity, with the model showing that an average of $62.5 \%$ of incident photons are absorbed on the first pass through the rhabdoms and a further $22.6 \%$ following reflection at the tapetum. Any light not absorbed is emitted from the eye as eyeshine which can seriously compromise the camouflage of the shrimps, leading to adaptations such as holes in the tapetum (Shelton et al., 1992) and the "eyeblink" response (Shelton et al., 2000) designed to reduce unwanted reflections. The eyeshine spectrum is significantly changed from that of downwelling light (or any other source) by the combined effects of tiering of the rhabdoms and self-screening by the visual pigments (Fig. 3). The effect of the distal rhabdom is to selectively remove short wavelength light and to produce a narrowing of the spectrum. This is countered by self-screening where the rhodopsin in the proximal rhabdom selectively removes light around the $\lambda_{\max }$ of its visual pigment. The overall effect is that the eyeshine has a broader spectrum shifted to a shorter $\lambda_{\max }$. The ability to detect eyeshine, both for prey detection and predator avoidance, is clearly of benefit. A two-pigment system would be necessary if such reflections are to be distinguished from the background on the basis of the spectral composition of the light. 


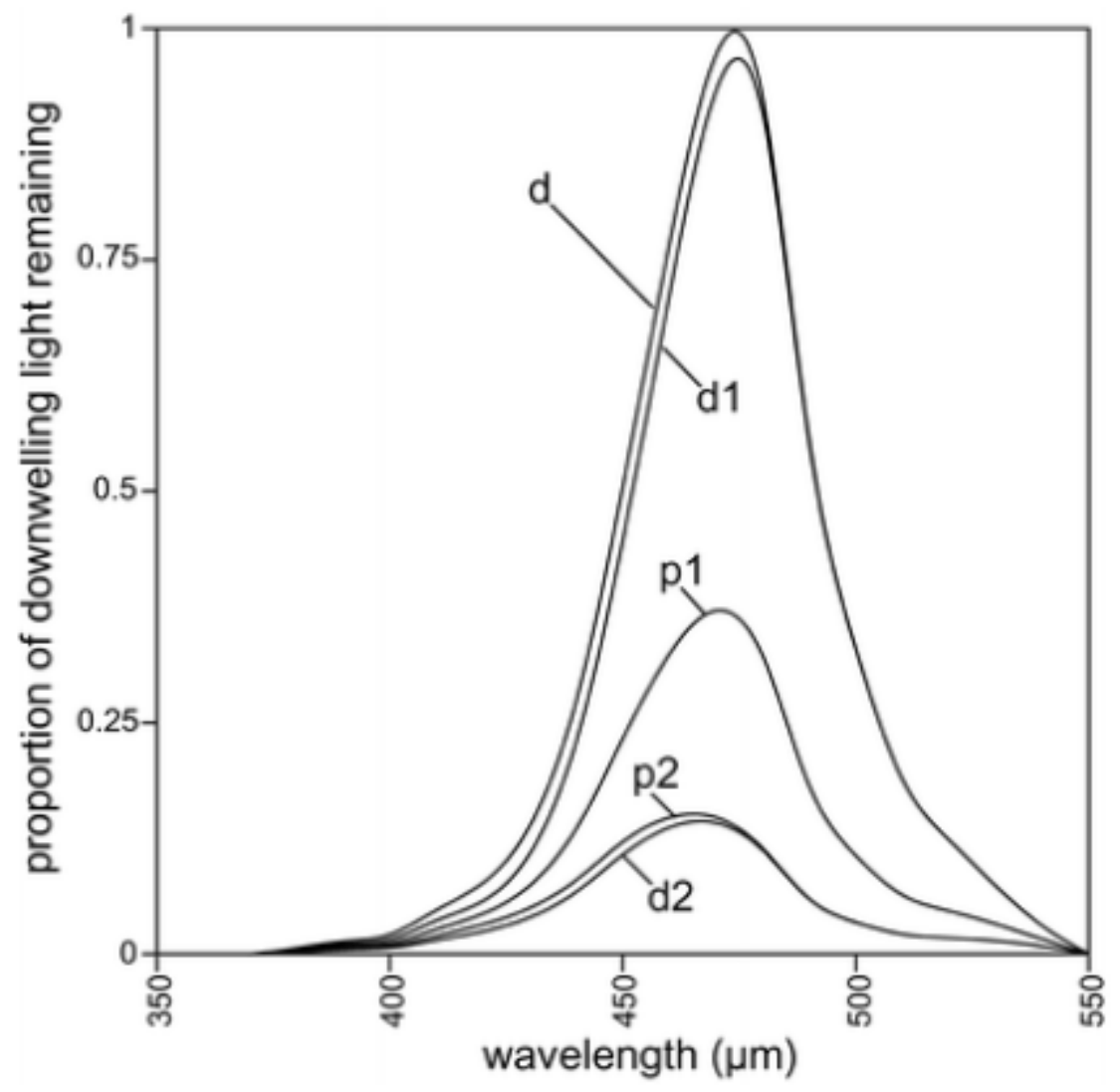

Fig. 3. Systellaspis debilis The absorption of downwelling light (d) by lateral rhabdoms showing the proportion of quanta remaining after passage through the distal rhabdom (d1), the proximal rhabdom (p1), the proximal rhabdom again (p2) following tapetal reflection, and finally through the distal rhabdom (d2). The latter represents the eyeshine emission spectrum.

Modeling the single pigment eye showed that in Acanthephyra pelagica comparable values of $F$ were obtainable for all sources even though the mean rhabdom length was shorter (130 $\mu \mathrm{m}$ compared to $160 \mu \mathrm{m}$ in Systellaspis debilis). When rhabdoms of the same length were modeled, the lateral rhabdoms of $A$. pelagica absorbed between $5 \%$ (for bioluminescent secretions) and 9\% (eyeshine) more than those of S. debilis. This is in accordance with the sensitivity hypothesis (Bayliss et al., 1936; Clarke, 1936) which argues that a visual pigment with a maximum absorbance $\left(\lambda_{\max }\right)$ that matches the wavelength of peak transmission of seawater would result in maximum visual sensitivity. Any visual pigment with a $\lambda_{\max }$ of between 465 and $495 \mu \mathrm{m}$ 
would result in high absorbance, particularly for downwelling light and other sources with similar $\lambda_{\max }$.

The dorso-ventral structural variations in the rhabdoms of Systellaspis debilis seem to be correlated with changes in the light environment above and below the animal. In mesopelagic crustaceans, double eyes are often found in which the upper eyes are used to detect silhouettes against the downwelling light and the lower eyes are used for detecting bioluminescence (Land, 2000). The dorsal part of the eye of Systellaspis debilis is adapted for higher resolution (Gaten et al., 2003) and high sensitivity to the downwelling light; it is thus well adapted for detecting silhouettes overhead. Over the rest of the eye, the rhabdoms are densely packing and have an enlarged distal rhabdom, leading to increased contrast sensitivity. This is ideal for detecting light reflected or emitted from targets against the background spacelight, as predicted by the contrast hypothesis (Lythgoe, 1979). Those shrimps living deeper in the mesopelagic zone (such as Acanthephyra pelagica) have abandoned the distal rhabdom in order to increase the total quantum capture, as predicted by the sensitivity hypothesis (Clarke, 1936; Bayliss et al., 1936).

\section{Acknowledgments.}

This work was supported by NERC grant GR3/11212. MSN gratefully acknowledges sabbatical support from Providence College. We would like to thank Justin Marshall (University of Queensland) for making available his data on the reflectance of carapace and tapetum of S. debilis. We thank Magnus Johnson for his valuable comments on an earlier draft of the manuscript. 


\section{References}

Bayliss LE, Lythgoe JN, Tansley K (1936) Some forms of visual purple in sea fishes with a note on the visual cells of origin. Proc R Soc (Ser B) 120: 95-114

Clarke RL (1936) On the depths at which fishes can see. Ecology 17: 452-456

Cronin TW, Frank TM (1996) A short-wavelength photoreceptor class in a deep-sea shrimp. Proc R Soc (Ser B) 263: 861-865

Denton EJ (1990) Light and vision at depths greater than 200 metres. In: Herring PJ, Campbell AK, Whitfield M, Maddock L (eds) Light and life in the sea. pp 127148. University Press, Cambridge

Frank TM, Case JF (1988) Visual spectral sensitivities of bioluminescent deep-sea crustaceans. Biol Bull mar boil Lab, Woods Hole 175: 261-273

Frank TM, Widder EA (1994a) Evidence for behavioural sensitivity to near-UV light in the deep-sea crustacean Systellaspis debilis. Mar Biol 118: 279-284

Frank TM, Widder EA (1994b) Comparative study of behavioral-sensitivity thresholds to near-UV and blue-green light in deep-sea crustaceans. Mar Biol 121: $229-235$

Frank TM, Widder EA (1996) UV light in the deep-sea: in situ measurements of downwelling irradiance in relation to the visual threshold sensitivity of UVsensitive crustaceans. Mar Fresh Behav Physiol 27: 189-197

Gaten E, Shelton PMJ, Herring PJ (1992) Regional morphological variations in the compound eyes of mesopelagic decapods in relation to their habitat. J mar biol Ass UK 72: 61-75 
Gaten E, Herring PJ, Shelton PMJ (2002) Eye morphology and optics of the doubleeyed mysid Euchaetomera typica. Acta Zool 83: 221-230

Gaten E, Shelton PMJ, Nowel MS (2003) Interspecific variations in the morphology and ultrastructure of the rhabdoms of oplophorid shrimps. J Morphol 257: 87-95 Herring PJ (1983) The spectral characteristics of luminous marine organisms. Proc R Soc (Ser B) 220: 183-217

Hiller-Adams P, Widder EA, Case JF (1988) The visual pigments of four deep-sea crustacean species. J comp Physiol 163: 63-72

Kampa EM (1970) Underwater daylight and moonlight measurements in the Eastern North Atlantic. J mar biol Ass UK 50, 397-420

Kent J (1997) The visual pigments of deep-sea crustaceans. PhD thesis, pp 383 University of Bristol

Kirk JTO (1983) Light and photosynthesis in aquatic ecosystems. University Press, Cambridge

Land MF (1989) The eyes of hyperiid amphipods: relations of optical structure to depth. J comp Physiol 164: 751-762

Land MF (2000) On the function of double eyes in midwater animals. Phil Trans R Soc (Ser B) 355: 1147-1150

Land MF, Burton FA, Meyer-Rochow VB (1979) The optical geometry of euphausiid eyes. J comp Physiol 130: 49-62

Laughlin SB (1981) Neural principles in the peripheral visual systems of invertebrates. In: Autrum H (ed) Handbook of sensory physiology, vol VII/6B, pp133-280. Springer-Verlag, Berlin 
Lythgoe JN (1968) Visual pigments and visual range under water. Vis Res 8: 9771012

Lythgoe JN (1979) The ecology of vision. Clarendon Press, Oxford

Nässel DR (1976) The retina and retinal projection on the lamina ganglionaris of the crayfish Pacifastacus leniusculus Dana. J comp Neurol 167: 341-360

Nowel MS, Shelton PMJ, Herring PJ (1998) Cuticular photophores of two decapod crustaceans, Oplophorus spinosus and Systellaspis debilis. Biol Bull mar boil Lab, Woods Hole 195: 290-307

Partridge JC, Archer SN, Lythgoe JN (1988) Visual pigments in the individual rods of deep-sea fishes. J comp Physiol 162: 543-550

Shelton PMJ, Gaten E, Herring PJ (1992) Adaptations of tapeta in the eyes of mesopelagic decapod shrimps to match the oceanic irradiance distribution. J mar biol Ass UK 72: 77-88

Shelton PMJ, Gaten E, Johnson ML, Herring PJ (2000) The 'eye-blink' response of mesopelagic Natantia, eyeshine patterns and the escape reaction. Crust Issues 12: 253-260

Stavenga DG, Smits RP, Hoenders BJ (1993) Simple exponential functions describing the absorbance bands of visual pigment spectra. Vis Res 33: 1011-1017

Tyler JE, Smith RC (1970) Measurements of spectral irradiance underwater. Gordon and Breach, New York, London, Paris.

Wald G, Rayport S (1977) Vision in annelid worms. Science 196: 1434-1439

Warrant EJ, Nilsson D-E (1998) Absorption of white light in photoreceptors. Vis res 38: 195-207 
Welsh JH, Chace FA (1937) Eyes of deep-sea crustaceans. Acanthephyridae. Biol Bull mar boil Lab, Woods Hole 72: 57-74

Welsh JH, Chace FA (1938) Eyes of deep-sea crustaceans. Sergestidae. Biol Bull mar boil Lab, Woods Hole 74: 364-375 